\title{
TRÊS EMPRESAS E UM EMPREENDEDOR: CASO DE ENSINO DE INTERNACIONALIZAÇÃO
}

Monalisa Tatiane De Medeiros Freitas ${ }^{1}$ Yákara Vasconcelos Pereira ${ }^{2}$

Vinicius Moreira ${ }^{3}$

Karla Rosane Do Amaral Demoly ${ }^{1}$

\footnotetext{
${ }^{1}$ Universidade Federal Rural do Semi-Árido

${ }^{2}$ Universidade Federal de Pernambuco - UFPE

${ }^{3}$ Universidade Federal de Campina Grande
} 


\section{Três Empresas e um Empreendedor: Caso de Ensino de Internacionalização}

Resumo: Com sede na cidade de João Pessoa (PB), as empresas A, B e C desenvolvem suas atividades no segmento de tecnologias e mídias digitais. Ao longo dos anos, devido à qualidade de seus produtos e capacidades inovadoras, dominaram o mercado regional e, de forma gradativa, estão conquistando os mercados nacionais e internacionais. Possuem o mesmo empreendedor e uma equipe engajada na busca por novos desafios. Neste caso de ensino fundamentado completamente em fatos reais, com o intuito de conduzir o leitor ao papel de dirigente, para que, com base na literatura de administração estratégica, negócios internacionais e empreendedorismo internacional, possa refletir sobre a realidade vivenciada pelas organizações e decidir qual o melhor caminho para consolidação no mercado internacional, assim relata-se o histórico do gestor e das organizações, assim como a descrição do processo de internacionalização e os métodos de gerenciamento marcados pela inovação.

Palavras-chave: Internacionalização. Inovação. Pequenas Empresas. Empreendedorismo internacional.

\section{Agradecimentos}

Agradecemos pelo apoio financeiro advindo do Edital Universal $2016 \mathrm{CNPq}$ - projeto $\mathrm{n}$. 431471/2016-9; e, Edital Universal 2018 (Chamada MCTIC/CNPq No 28/2018) - projeto n. $405109 / 2018-0$

\section{$1 \quad$ Introdução}

O grupo empresarial composto pelas empresas A, B e C está inserido na Paraíba (PB), uma região de forte potencial econômico, destacado pela formação do Parque Tecnológico da Paraíba (PAQTCPB), cuja principal característica é a intensa articulação entre instituições públicas de ensino e pesquisa, fundações, organizações empresariais, e outros órgãos de fomento à pesquisa e desenvolvimento tecnológico que se tornam sujeitos do planejamento e somam esforços para viabilizar projetos e ações voltados para o desenvolvimento regional (BARREIRO, 2015).

Os Parques Científicos e Tecnológicos (PCTs) são abordados na literatura mundial como essenciais para o desenvolvimento territorial, a integração econômica e a criação de inovações tecnológicas. São ambientes fortemente marcados pela inovação e implantados em países desenvolvidos e em desenvolvimento para dinamizar economias regionais e nacionais, agregando-lhes conteúdo de conhecimento e consequentemente tornando as economias mais competitivas no cenário internacional. As ações dos Parques Científicos e Tecnológicos são enraizadas no conceito de hibridização interorganizacional, significando que organizações distintas se inter-relacionam e cooperam entre si para alcançar resoluções possíveis entre as esferas institucionais da universidade, governo e empresa gerando estratégias alternativas para o crescimento econômico e a transformação social (BARREIRO, 2015). A partir dessa articulação, surge a oportunidade para as organizações paraibanas utilizarem a inovação para se desenvolverem nos setores de tecnologia e mídias digitais nos mercados nacionais e 
internacionais. Eclodem e prosperam as chamadas Empresas de Base Tecnológica (EBTs) que são caracterizadas pelo uso intensivo de conhecimento científico tecnológico e pela interação com institutos de ensino e pesquisa locais, a fim de obter conhecimentos imprescindíveis às suas atividades (AGUIAR, 2001). A comunicação digital e o uso das tecnologias digitais se popularizaram no ambiente da comunicação abrindo um campo de inovações, criatividade, dinamismo e uma sucessão de posicionamentos, usos e escolhas que acabaram por criar incompreensões, inadequações e entraves no desenvolvimento da organização (CORRÊA, 2005). Diante disso, apesar da oportunidade de expandir e se consolidar no mercado pelo seu aspecto dinâmico e interativo, algumas dessas organizações inovadoras ainda encontram desafios relacionados ao conhecimento quando tentam empreender e internacionalizar.

Dentro desse cenário, o grupo empresarial se desenvolveu e obteve destaque em nível regional, obtendo alguns clientes nacionais e internacionais. No entanto, apesar da qualidade de seus produtos e do alinhamento de suas atividades, algumas estratégias são necessárias para a expansão e consolidação de suas atividades internacionais.

Para o levantamento dessas informações junto às organizações, foram realizadas entrevistas semiestruturadas com gestores, colaboradores e antigos estagiários das organizações. Sendo eles:

\begin{tabular}{|c|l|}
\hline Sujeitos Entrevistados & \multicolumn{1}{c|}{ Características } \\
\hline Lucas & $\begin{array}{l}\text { Discente do 8 período do Curso de Comunicação e Mídias digitais da } \\
\text { Universidade Federal da Paraíba (UFPB), com experiência em empresas } \\
\text { juniores, foi estagiário da Qualitare por aproximadamente 8 (oito) meses. }\end{array}$ \\
\hline \multirow{3}{*}{ Nohan } & $\begin{array}{l}\text { Discente do Curso de Comunicação e Mídias digitais da Universidade } \\
\text { Federal da Paraíba (UFPB), foi estagiário na Qualitare por 3 (três) meses } \\
\text { desenvolvendo vídeos e motion design. Atualmente trabalha em uma } \\
\text { agência de marketing digital na Paraíba. }\end{array}$ \\
\hline \multirow{3}{*}{ Matheus } & $\begin{array}{l}\text { Discente do Curso de Comunicação e Mídias digitais da Universidade } \\
\text { Federal da Paraíba (UFPB), foi estagiário na Qualitare por 7 (sete) meses } \\
\text { desenvolvendo vídeos e motion design. Atualmente possui sua própria } \\
\text { empresa de produção e edição de vídeos. }\end{array}$ \\
\hline \multirow{3}{*}{ Fabiana } & $\begin{array}{l}\text { Gestora do setor Administrativo-Financeiro na Qualitare há } \\
\text { aproximadamente 8 (oito) anos. Acompanhou todo o crescimento e } \\
\text { desenvolvimento das organizações. }\end{array}$ \\
\hline Jitana & $\begin{array}{l}\text { Graduada em jornalismo pela Universidade do Estado da Paraíba (UEPB), } \\
\text { Mestre em Comunicação e Culturas Midiáticas pela Universidade Federal } \\
\text { da Paraíba (UFPB), écolaboradora da Qualitare há aproximadamente 2 } \\
\text { (dois) anos, foi gestora do Departamento de Mídias Digitais e atualmente } \\
\text { é integrante da equipe de Desenvolvimento de projetos. }\end{array}$ \\
\hline Juarez & Fundador e Diretor das três empresas analisadas. \\
\hline
\end{tabular}

Figura 1. Identificação dos entrevistados

Fonte: Elaboração dos autores (2019).

Após a coleta de dados, com auxílio do software Atlas.ti (versão 8), foram realizadas análises de conteúdo (BARDIN, 2011) para identificar conexões, códigos e categorias que auxiliassem na compreensão do processo de evolução do grupo empresarial.

A seguir, com intuito de fomentar a reflexão acerca das estratégias necessárias à consolidação das empresas no mercado internacional, descreve-se o histórico e o processo de 
internacionalização, assim como apresenta-se os principais aspectos inovadores encontrados no grupo empresarial.

\title{
$2 \quad$ Histórico das Empresas
}

Aos treze anos de idade, Juarez interessou-se pelo desenvolvimento de sites, iniciando estudos e pesquisas na área da tecnologia de forma autodidata. Aos quinze anos, ele foi selecionado para um estágio em uma empresa na área de tecnologia, onde pode aprimorar seu conhecimento durante 3 (três) anos, sendo selecionado pela UNIMED aos dezoito anos para compor a equipe de desenvolvimento do portal da intranet.

Após a finalização do projeto, Juarez sentiu a necessidade de buscar novos desafios, fundando a empresa A, que viria a ser a primeira empresa do grupo empresarial, conforme relato a seguir:

\begin{abstract}
Aos 18 anos fui trabalhar na Unimed para desenvolver o portal intranet e acho que quando estava com 21 anos já estava entediado porque tinha desenvolvido o portal intranet e eu sentia que por mais que na minha idade eu tivesse tido uma recompensa financeira bacana, não era aquilo que me movia, eu era muito mais movido a ter uma sensação de realização por estar fazendo alguma coisa que pra mim fosse relevante [...]. Pedi demissão e foi quando abri a empresa A. (JUAREZ, 2018).
\end{abstract}

A empresa A foi iniciada em 11 de dezembro de 2006 com as economias e os clientes que Juarez possuía como autônomo, sem estrutura física definida e sem investimentos externos. Com o passar dos anos, a organização foi se desenvolvendo, conquistando novos clientes, e se estabilizando financeiramente. Durante seis anos a empresa A foi um estúdio que produzia sites, em seguida tornou-se uma agência de mídias digitais, e atualmente, nos últimos dois anos, está investindo na área de startups.

Ao longo desses doze anos de existência do empreendimento, alguns novos desafios e oportunidades de mercado foram surgindo para Juarez. A partir disso, ele fundou as empresas B e C para atender demandas que a empresa A ainda não acolhia. A firma B focou no desenvolvimento de aplicativos e games, enquanto a empresa $\mathrm{C}$ responsabilizava-se pelo desenvolvimento de novas ideias e produtos escaláveis. O grupo formado pelas três empresas passou a funcionar no mesmo prédio, no entanto, possuía equipes distintas, conforme relato a seguir:

São três empresas, só que ficam todas aqui, na mesma estrutura. Porque, no final das contas, é o seguinte: a empesa A era agência do grupo, a B desenvolvia aplicativos e games para empresas terceiras e a $\mathrm{C}$ é quem tanto investia nos produtos próprios, ela meio que bancava os produtos próprios. (JUAREZ, 2018)

A empresa B foi fundada em 10 de outubro de 2014 com Juarez e mais três sócios atuando no setor de desenvolvimento de aplicativos e games. Posteriormente, além dos sócios, havia um gerente de projetos e dois estagiários. Após alguns projetos desenvolvidos para o mercado nacional e internacional, em 2018, os sócios decidiram trilhar novos caminhos e a sociedade foi desfeita informalmente, estando em processo de alteração de seus documentos 
de registro para dissolução formal da sociedade. Diante disso, a empresa B está efetivamente desenvolvendo suas atividades apenas com Juarez, sem mais colaboradores.

Em paralelo à fundação da empresa $\mathrm{B}$, houve a fundação do empreendimento $\mathrm{C}$, também em 10 de outubro de 2014. No entanto, a empresa C partiu de uma iniciativa de Juarez de atuar no desenvolvimento de novas ideias e produtos digitais escaláveis, não tendo sócios ou colaboradores nessa organização.

A seguir, na figura 2, pode-se observar um quadro resumido das principais informações das organizações do grupo empresarial.

\begin{tabular}{|c|c|c|c|c|}
\hline Empresas & $\begin{array}{c}\text { Data de } \\
\text { Fundação }\end{array}$ & Porte & Atividade Econômica Principal & $\begin{array}{l}\text { Quantidade de } \\
\text { Funcionários }\end{array}$ \\
\hline A & $11 / 12 / 2006$ & $\begin{array}{l}\text { Empresa de } \\
\text { Pequeno Porte } \\
\text { (EPP) }\end{array}$ & $\begin{array}{l}\text { - Comunicação digital, tecnologia e } \\
\text { inovação. } \\
\text { - Suporte técnico, manutenção e outros } \\
\text { serviços de TI. }\end{array}$ & 13 \\
\hline B & $10 / 10 / 2014$ & $\begin{array}{l}\text { Microempresa } \\
\text { (ME) }\end{array}$ & $\begin{array}{l}\text { - Desenvolvimento de aplicativos e } \\
\text { games. } \\
\text { - Portais, provedores de conteúdo e } \\
\text { outros serviços de informação. }\end{array}$ & 4 \\
\hline $\mathrm{C}$ & $10 / 10 / 2014$ & $\begin{array}{l}\text { Microempresa } \\
\text { (ME) }\end{array}$ & $\begin{array}{l}\text { - Fomentar o desenvolvimento de novas } \\
\text { empresas e ideias no setor de tecnologia } \\
\text { digital. } \\
\text { - Portais, provedores de conteúdo e } \\
\text { outros serviços de informação. }\end{array}$ & 1 \\
\hline
\end{tabular}

\section{Figura 2. Informações das empresas do grupo empresarial}

Fonte: Elaboração dos autores (2019).

As organizações foram se desenvolvendo e obtendo destaque dentro de seus setores, principalmente a empresa A por já possuir 12 anos no mercado, uma carteira de clientes bem estabelecida, uma estrutura organizacional definida, produtos e serviços com qualidade, além de perfil inovador e alta capacidade criativa. Atualmente, a empresa A é considerada a empresa de marketing digital mais inovadora da região, conforme relato de uma colaboradora: "A firma A hoje, no mercado de João Pessoa, é tida como a empresa de marketing digital mais inovadora." (FABIANA, 2018).

Com essa conquista do mercado regional, veio a oportunidade de desenvolver produtos e serviços para empresas de reconhecimento nacional, conforme demonstra o relato a seguir:

\footnotetext{
Na empresa A temos parceria com agências de comunicação em São Paulo, e como eles gostam do nosso trabalho, eles meio que nos terceirizam para desenvolvermos algumas coisas, digamos que essas agências trabalham marca no nível global, então uma agência que tem dois pontos da Ambev, da Honda, eles dizem "preciso de tais projetos no digital, vocês desenvolvem pra gente?" Desenvolvemos. Tem essa parceria em nível de ser braço digital de algumas agências e isso serve tanto para a empresa A, quanto para a B. (JUAREZ, 2018).
}

Diante dessa expansão para o mercado nacional e o perfil inovador do empreendedor, as organizações passaram a centralizar suas atividades no desenvolvimento de aplicativos e produtos escaláveis e globais, estabelecendo como novo desafio para o grupo empresarial a 
conquista de mercados internacionais, dando início as primeiras etapas do processo de internacionalização.

\title{
$3 \quad$ Processo de Internacionalização
}

A partir dessa perspectiva de desenvolvimento de produtos digitais próprios com possibilidade de escalar, o grupo desenvolveu o aplicativo InSpy que tem como finalidade o monitoramento dos contatos estabelecidos como "preferidos" na rede social Instagram, acompanhando o que eles estão "curtindo", "comentando" e as páginas que eles estão "seguindo". Após a apresentação do aplicativo no TechCrunch Disrupt Conference no Vale do Silício (Califórnia/EUA) em 2015, e no Web Summit (Lisboa/PT) em 2017, o grupo empresarial ultrapassou as barreiras de negócios nacionais, passando a ter usuários e clientes em diversos países do mundo todo, conforme demonstrado a seguir:

\begin{abstract}
Nós já desenvolvemos projetos em outros países, inclusive, um dos produtos que nós desenvolvemos como startup, que é o InSpy, nós apresentamos no Vale do Silício, no evento chamado TechCrunch, que é o maior evento de startup do mundo, nós apresentamos também na Web Summit, que é um evento muito grande de tecnologia lá em Portugal. Eles contribuíram muito para a internacionalização desse projeto porque, em um evento desses, além de conhecermos grandes players, também temos contato com a imprensa, eles fazem networking, então, surge a divulgação dos projetos. (JUAREZ, 2018)
\end{abstract}

A partir dos documentos fornecidos pelas organizações, pode-se constatar que o InSpy atualmente possui mais de seiscentos mil usuários ativos distribuídos em países como África do Sul, Austrália, Canadá, Chile, China, Coreia do Sul, Croácia, Dinamarca, Emirados Árabes, Hong Kong, Hungria, Índia, Indonésia, Israel, Japão, Malásia, México, Noruega, Nova Zelândia, Peru, Polônia, Reino Unido, Romênia, Rússia, Singapura, Suécia, Suíça, Tailândia, Turquia e Vietnã, o que demonstra o fortalecimento do seu processo de internacionalização ao levar em consideração o expressivo número de usuários de diferentes países que instalam e utilizam ativamente o aplicativo.

Além dessa experiência internacional com o aplicativo InSpy, o grupo empresarial concretizou contratos com clientes suíços para desenvolvimento de dois aplicativos de delivery de bebidas, e com o Grupo Mantra de hotéis e resorts presentes em vários países. Com essa vivência, as organizações estão redesenhando suas estratégias e direcionando suas ações para o desenvolvimento de produtos e serviços para o mercado mundial, conforme relato:

Sim, o nosso foco vai ser criar produtos de escala global. Então, isso já está entrando no nosso DNA. Basicamente, vai ser nosso principal produto, ele aceita quarenta por cento dos usuários do fórum do exterior, entendeu? Então, hoje nós temos muitos clientes fora e clientes em desenvolvimento também. (JUAREZ, 2018)

Diante dessa nova estratégia de direcionamento para o mercado global, o grupo está em processo de transição:

Aí, o que é que nós estamos fazendo? Nós vamos transformar tudo em uma coisa só. Porque está tudo muito interligado, e aí o serviço que não tem escala, que é a parte de 
mídias digitais, a gente está cortando da Qualitare, entendeu? Justamente porque é uma área que a gente não acredita que vai ter impacto positivo a longo prazo, sabe? (JUAREZ, 2018)

De acordo com o proprietário e gestor, nesse novo modelo, as três empresas seriam transformadas em uma só que teria capacidade para atender às demandas do mercado nacional e internacional. No entanto, esse processo ainda está em andamento e as empresas estão sendo analisadas para que sejam eliminados produtos e serviços não escaláveis e que não tragam impactos positivos a longo prazo.

\section{Aspectos inovadores das Organizações}

Observa-se que as organizações apresentam inúmeros fatores preponderantes para consolidar o fenômeno do empreendedorismo internacional. Tais aspectos, conhecidos como dimensões, consistem em desafios a serem ultrapassados pelas empresas para comercializarem produtos e serviços no mercado exterior (PEREIRA; MORAES, 2014; PEREIRA; MORAES; SALAZAR, 2017; MACHADO; PEREIRA, 2016; PEREIRA; MORAES; SALAZAR, 2016a; PEREIRA; MORAES; SALAZAR, 2016b). No framework analítico de empreendedorismo internacional proposto por Pereira e Moraes (2014), observa-se que atitude face ao risco, capacidade de inovar, oportunidade, propensão à adaptação, comercialização arrojada, desenvolvimento de recursos competitivos, empreendedor internacional e redes de relacionamentos são dimensões presentes no processo de internacionalização de uma empresa.

Nas organizações em questão, observa-se uma expressiva capacidade de inovar a partir da incidência de alguns aspectos destacados na literatura como motivadores da inovação e da internacionalização. Dentre esses aspectos, pode-se destacar a capacidade de internacionalizar, as capacidades técnicas e pessoais, a estratégia organizacional, a evolução de produtos e mercados, a flexibilidade para reconhecer oportunidades, o gerenciamento de recursos, a tecnologia e a vantagem competitiva (FREITAS, 2019).

As organizações apesentam capacidade de internacionalizar a partir do momento em que direcionam suas estratégias para o desenvolvimento de produtos escaláveis e globais, passando a utilizar seu potencial inovador para a evolução dos processos de crescimento (KOSALA, 2015). A partir desse desenvolvimento de produtos e serviços direcionados para o mercado global, além de participar constantemente de eventos, as organizações começaram a apresentar seus produtos em eventos mundiais de tecnologia e inovação com o intuito de alcançar novos mercados e fomentar sua capacidade de internacionalização, corroborando a perspectiva de que ao ultrapassar as fronteiras nacionais, as organizações devem desenvolver suas capacidades de internacionalizar (PRANGE; VERDIER, 2011), a saber:

Então, acho que a primeira coisa é a inovação. O fator de ineditismo de lançar um projeto que tem um potencial de divulgação boca a boca, e estar nos eventos onde as pessoas mais inovadoras do mundo estavam, isso aí acabou gerando um plus, uma repercussão. (JUAREZ, 2018)

Além disso, para que a inovação ocorra dentro dos padrões e possibilite a internacionalização, as organizações precisam fortalecer seu capital humano e desenvolver competências na evolução de novos produtos, serviços e tecnologias (CHEN; HUANG, 2009). 
Relacionado a isso, destaca-se as capacidades técnicas e pessoais dos dirigentes das organizações. Aspectos como o networking nacional e internacional, a organização financeira do grupo, as habilidades que os gestores possuem com negociação, a organização estrutural das empresas e os perfis inovadores foram constantemente destacados pelos respondentes como impulsionadores do processo de inovação e internacionalização das empresas. Em relação ao perfil inovador dos dirigentes, foram destacadas trinta e quatro citações que fortalecem esse aspecto como diferencial nas estratégias das organizações. De acordo com um dos gestores, além de Juarez ser ambicioso e buscar sempre um objetivo maior a ser alcançado, também possui a cultura de não especificar um responsável pela inovação dentro das organizações. Assim, busca que toda a equipe tenha esse potencial inovador e utilizam estratégias organizacionais para impulsionar esse comportamento, o que demonstra uma capacidade de gestão que constitui expressivo antecedente para a visão inovadora (HOOLEY et al., 2005), o relato a seguir fortalece essa compreensão:

\footnotetext{
Então, nós não colocamos um responsável por isso. A gente tenta incluir isso na cultura da empresa, no pensamento. Tanto é que o nosso slogan é 'digital transborda', ou seja, nós precisamos estar sempre transbordando, onde quer que trabalhemos. Não tem um responsável: ah, eu vou puxar a inovação. Não. A inovação tem que vir de cada um, é um comportamento que nós exigimos, que atrai pessoas que tenham essa característica. (JUAREZ, 2018)
}

Relacionado às capacidades técnicas e pessoais, tem-se a necessidade dos gestores serem flexíveis para reconhecer e adaptar as organizações às novas oportunidades. Foi relatado que para o desenvolvimento de novos produtos como o InSpy houve uma análise de tendências para identificar um nicho inexplorado de mercado a ser desbravado, o que corrobora a perspectiva de que muitas vezes apesar das pequenas empresas não serem capazes de competir em preço com os empreendimentos globais, sua capacidade de renovar e adequar seus recursos, associados à sua flexibilidade para reconhecer novas oportunidades e adaptar a estratégia de mercado para os mercados internacionais, são consideradas vantagens estratégicas significativas (SOK; O'CASS, 2015).

A partir dessa flexibilidade para reconhecer oportunidades, tem-se a necessidade de evolução que remete à implantação contínua de recursos organizacionais e desenvolvimento de novos produtos e mercados (WANG; AHMED, 2004). Em relação às organizações analisadas nesse estudo, pode-se observar no histórico das empresas que inicialmente o modelo de negócio da empresa A era semelhante ao de agências digitais, evoluindo ao longo dos anos para um modelo de organização direcionado aos produtos escaláveis e globais, além do desenvolvimento das empresas B e C para fortalecer o mercado de aplicativos. Além dessa mudança estratégica, alguns colaboradores destacam a constante preocupação da equipe com a qualidade dos produtos e serviços, sempre aprimorando os produtos já consolidados ou inovando na criação de novos produtos, conforme destacado a seguir por uma colaboradora: "É sempre dinâmico. Os projetos tendem a ser melhores do que outros, sempre superar aqueles anteriores que a gente já entregou. E eu vejo isso também, eles tentam sempre buscar inovação no que a gente faz." (FABIANA, 2018).

Atrelada a essa evolução de produtos e mercados baseados na inovação, tem-se a tecnologia. A partir dos dados coletados, infere-se que a tecnologia é primordial para as organizações. Para os respondentes, além de ser utilizada para o desenvolvimento de 
novos produtos e serviços, a tecnologia também recebe destaque por exercer papel de facilitador da comunicação e do processo de inovação, demonstrando que as pequenas empresas quando focadas em tecnologia costumam se destacar pela utilização de ferramentas e meios de comunicação disponíveis que geram impacto sobre a oportunidade da ocorrência da empresa nos mercados internacionais quase com efeito imediato (KOSALA, 2015). O relato a seguir demonstra a importância e as possibilidades que a tecnologia oferece ao grupo empresarial:

Eu acho que a busca pela expansão. Esse mercado de tecnologia permite muito você buscar novos horizontes. E você não tem a limitação geográfica, porque você pode fazer as reuniões por Skype. Então, quando você trabalha com tecnologia, essas barreiras se dissolvem. A gente vê uma nova forma de trabalho surgindo, dando espaço e facilitando para que a gente consiga realizar novos trabalhos. Então eles passavam para gente o briefing, era feito e tudo era mandado digitalmente. Tudo mandado pela internet, então não tinha dificuldade. (JITANA, 2018)

Essa otimização dos recursos tecnológicos relaciona-se com o gerenciamento dos recursos estruturais e humanos. Em relação aos recursos estruturais, as organizações priorizam equipamentos modernos e um ambiente estrutural agradável para todos os colaboradores sentirem-se confortáveis para inovar e possuírem equipamentos tecnológicos de ponta disponíveis. Quanto aos recursos humanos, nota-se uma preocupação com a evolução dos colaboradores rumo à inovação. Apesar dos dados coletados ressaltarem o alto nível de qualidade da equipe, as organizações possuem um programa de incentivo em que as empresas custeiam $50 \%$ de qualquer treinamento ou curso, inclusive de graduação, que os colaboradores tenham interesse em realizar, além de outros benefícios como plano odontológico, seguro de vida, ticket refeição, assinaturas no Netflix e Spotify, flexibilidade de horários e vestimentas, e ambientes de interação na empresa com videogame e piscina. Por fim, há ainda a preocupação dos gestores em realizar reuniões semanais para discutir com os colaboradores os novos projetos e o posicionamento dos projetos que estão em andamento, assim como proporcionar um ambiente favorável ao compartilhamento de ideias e sugestões, favorecendo a inovação e seguindo a perspectiva de realizar altos investimentos em recursos humanos avançados para alcançar desempenho superior (COLLINS; CLARK, 2003).

Com todos esses aspectos, o grupo conseguiu adquirir vantagens competitivas dentro do mercado de João Pessoa (PB) sendo reconhecida como a empresa de marketing digital mais inovadora. Diante disso, surge a necessidade de expansão para novos mercados com base em suas capacidades de inovar no intuito de gerar vantagens competitivas globais (AUTIO; SAPIENZA; ALMEIDA, 2000; MELIA; PEREZ; DOBON, 2009), conforme demonstra o relato a seguir:

Eu acho que, a partir do momento que nós conquistamos o Brasil, em relação a clientes, por exemplo, desenvolvemos projetos para Honda, Band, ou seja, lá em São Paulo, multinacionais, aquilo ali tinha ficado pequeno para nós, entendeu? Então, à medida que nós vamos subindo os degraus, nós vamos exigindo mais. Então, o próximo degrau é global. Foi natural o que aconteceu. (JUAREZ, 2018)

Diante desses aspectos, observa-se que o grupo empresarial possui uma expressiva política organizacional concentrada na inovação para expansão de seus mercados por fortalecerem as dimensões que relacionam inovação e internacionalização. Com relação à capacidade de internacionalizar, identifica-se que a organização busca participar e 
divulgar seus produtos em eventos, assim como desenvolver produtos escaláveis e globais, tendo flexibilidade para reconhecer novas oportunidades e trabalhar na evolução de seus produtos e mercados relacionados à tecnologia. Em consonância a isso, há uma intensa preocupação com o gerenciamento de recursos físicos e humanos que contribuem significativamente para o desenvolvimento do grupo e a obtenção de vantagens competitivas nos mercados nacionais e internacionais. Dentre esses aspectos, destacam-se as capacidades técnicas e pessoais especificamente dos dirigentes, que devido a sua intensa relevância para o grupo empresarial, apresentou forte influência na dinâmica organizacional e na expansão das organizações. Levando em consideração os aspectos identificados pela literatura, pode-se inferir, a partir dos dados analisados, que apenas o aspecto da estratégia organizacional não se encontra presente nas organizações investigadas, contrapondo a perspectiva de Lam (2005), a qual reconhece que com modificações no sistema tecnológico e nos processos de gestão de uma firma, mudanças na área administrativa e estratégica tornam-se essenciais. Apesar da ausência dessa dimensão, as organizações apresentam potencial para consolidação de seus processos de internacionalização e os empreendedores merecem destaque por estarem desenvolvendo a inovação de forma expressiva como aspecto primordial a ser fortalecido em nível gerencial e operacional.

\section{$4 \quad$ Perspectivas}

Apesar das experiências internacionais, o grupo empresarial sente a necessidade de aprimorar suas atividades em busca da expansão e consolidação no mercado global. Diante disso, com intuito de fortalecer as empresas, Juarez e sua equipe estão trabalhando nessa nova estratégia de unificar as três empresas do grupo em uma só organização que atenda todas as demandas do mercado nacional e internacional, eliminando de seu portfólio os produtos e serviços que não tenham possibilidade de escalar. Seria essa a melhor opção? Como ele deveria executar esse processo para obter o retorno esperado? Ele deveria investir mais no planejamento desse processo de consolidação? Deveria focar em algum mercado específico? Nessa nova etapa, quais seriam os modos de entrada mais adequados no exterior? Juarez deveria investigar e analisar outras estratégias? Quais seriam as estratégias possíveis para essa consolidação no mercado internacional? Em relação à inovação, está sendo bem desenvolvida pelas organizações? Ela pode contribuir para essa consolidação no mercado internacional? Quais seriam as outras dimensões do empreendedorismo internacional que poderiam ser fortalecidas nesse processo? 


\section{Notas de Ensino}

O caso do grupo empresarial descreve o processo de surgimento e evolução de três empresas de pequeno porte, localizadas em uma capital do Nordeste brasileira, que partiram do sonho de um jovem empreendedor e em pouco mais de uma década alcançaram expressivo reconhecimento regional e nacional. Quanto ao processo de internacionalização, os empreendimentos forneceram alguns produtos e serviços para clientes de outros países e desenvolveram um aplicativo que possui usuários ativos no mundo todo, no entanto, ainda buscam novos desafios que consolidem suas atividades no mercado internacional.

Para essa consolidação, surge a necessidade de rever as estratégias organizacionais estabelecidas e realizar as adequações necessárias que contribuam com o desenvolvimento de produtos e serviços inovadores com capacidade de escalar e atingir outras economias.

\section{Utilização e objetivos do caso}

Este caso foi desenvolvido para ser aplicado no nível de graduação e pós-graduação nas disciplinas de empreendedorismo, estratégia empresarial, gestão de negócios, estratégia internacional e inovação. Os objetivos deste caso de ensino são:

- Proporcionar discussões acerca do empreendedorismo internacional, desenvolvendo considerações sobre suas dimensões, vantagens, desafios e motivações;

- Discutir as estratégias utilizadas nos processos de internacionalização;

- Analisar a relação entre inovação e internacionalização;

- Discutir o papel do gestor na exploração de oportunidades de mercado.

\section{Fonte de obtenção de dados}

Os dados que fundamentam a elaboração deste caso de ensino foram coletados em fontes bibliográficas e por meio de entrevistas semiestruturadas realizadas com o empreendedor, alguns colaboradores e ex-estagiários das organizações. Quanto às fontes bibliográficas, foram analisadas pesquisas que discutem empreendedorismo internacional e inovação, assim como os sites e as redes sociais das empresas. Para análise de dados foi utilizada a análise de conteúdo de Bardin (2011) com auxílio do software ATLAS.ti. 


\section{Referências}

AGUIAR, A. A. V. C. A transferência de informação tecnológica entre universidade e empresa do polo tecnológico de campina grande-pb. Informação \& Sociedade: Estudos, v. 11, n. 2, p. 01-09, 2001.

AUTIO, E.; SAPIENZA, H. J.; ALMEIDA, J. G. Effects of age at entry, knowledge intensity, and imitability on international growth. Academy Of Management Journal, [s.1.], v. 43, n. 5, p.909-924, 1 out. 2000. The Academy of Management.

BARDIN, Laurence. Análise de conteúdo. [s.1.]: Almedina, 2011. 280 p.

BARREIRO, Elis Regina Neves. O parque tecnológico da Paraíba e arranjos institucionais: tessituras do desenvolvimento local-territorial. 2015. 136 f. Dissertação (Mestrado) - Curso de Programa de Pós-Graduação em Desenvolvimento Regional, Universidade Estadual da Paraíba, Campina Grande, 2015.

CHEN, Chung-jen; HUANG, Jing-wen. Strategic human resource practices and innovation performance: The mediating role of knowledge management capacity. Journal of Business Research, v. 62, n. 1, p.104-114, jan. 2009. Elsevier BV.

COLLINS, C. J.; CLARK, K. D. Strategic Human resource practices, top management team social networks, and firm performance: The role of human resource practices in creating organizational competitive advantage. Academy of Management Journal, [s.1.], v. 46, n. 6, p.740-751, 1 dez. 2003. The Academy of Management.

CORRÊA, Elizabeth Saad. Comunicação digital: uma questão de estratégia e de relacionamento com públicos. Revista Brasileira de Comunicação Organizacional e Relações Públicas, São Paulo, v. 2, n. 3, p.95-111, 2005.

FREITAS, Monalisa Tatiane de Medeiros. Empreendedorismo internacional: a capacidade de inovar no grupo de empresas paraibanas de tecnologia digital. 2019. $89 \mathrm{f}$. Dissertação (Mestrado) - Curso de Programa de Pós-Graduação Interdisciplinar em Cognição, Tecnologias e Instituições (PPGCTI), Universidade Federal Rural do Semi-Árido, Mossoró, 2019.

HOOLEY, Graham J.; GREENLEY, Gordon E.; CADOGAN, John W.; FAHYB, John. The performance impact of marketing resources. Journal of Business Research, [s.1.], v. 58, n. 1, p.18-27, jan. 2005. Elsevier BV. 
KOSALA, Malgorzata. Innovation Processes as a Stimulant of Internationalisation Process of Firms. Entrepreneurial Business and Economics Review, [s.1.], v. 3, n. 2, p.65-84, 2015. Uniwersytet Ekonomiczny w Krakowie - Krakow University of Economics.

LAM, A. Organizational innovation. In J. Fagerberg, D. C. Mowery, \& R. R. Nelson (Eds.), The Oxford handbook of innovation. Oxford: Oxford UniversityPress, 2005, p. 115147.

MACHADO, Francisco Oliveira; PEREIRA, Yákara Vasconcelos. O EMPREENDEDOR E O PROCESSO DE INTERNACIONALIZAÇÃO DE EMPRESAS: Um Olhar à Atuação Empreendedora Além das Fronteiras Nacionais. Perspectivas Contemporâneas, [s.1.], v. 11, n. 1, p.34-54, abr. 2016.

MELIÁ, Maria Ripolles; PÉREZ, Andreu Blesa; DOBÓN, Salvador Roig. The influence of innovation orientation on the internationalisation of SMEs in the service sector. The Service Industries Journal, [s.1.], v. 30, n. 5, p.777-791, 5 nov. 2009. Informa UK Limited.

PEREIRA, Yákara Vasconcelos; MORAES, Walter Araújo de. As Dimensões do Empreendedorismo Internacional: Uma Proposição de um Framework. Revista Iberoamericana de Estratégia, [s.1.], v. 13, n. 04, p.91-106, 1 dez. 2014. University Nove de Julho.

PEREIRA, Yákara Vasconcelos; MORAES, Walter Fernando Araújo de; SALAZAR, Viviane Santos. EMPREENDEDORISMO INTERNACIONAL: UMA ANÁLISE DE EXPORTADORAS DO SEMIÁRIDO NORDESTINO. Revista de Administração, Contabilidade e Economia, [s.1.], v. 15, n. 2, p.531-552, ago. 2016 a.

PEREIRA, Yákara Vasconcelos; MORAES, Walter Fernando Araújo de; SALAZAR, Viviane Santos. INTERNATIONAL ENTREPRENEURSHIP IN AGRIBUSINESS. Revista Galega de Economía, [s.1.], v. 25, n. 1, p.151-162, 2016b.

PEREIRA, Yákara Vasconcelos; MORAES, Walter Fernando Araújo de; SALAZAR, Viviane Santos. Recursos competitivos no empreendedorismo internacional: uma análise qualitativa em empresas exportadoras. Gestão \& Produção, [s.1.], v. 24, n. 3, p.477-487, 29 jun. 2017. FapUNIFESP (SciELO).

PRANGE, Christiane; VERDIER, Sylvie. Dynamic capabilities, internationalization processes and performance. Journal of World Business, [s.1.], v. 46, n. 1, p.126-133, jan. 2011. Elsevier BV.

SOK, Phyra; O'CASS, Aron. Examining the new product innovation - performance relationship: Optimizing the role of individual-level creativity and attention-todetail. Industrial Marketing Management, [s.1.], v. 47, p.156-165, maio 2015. Elsevier BV. 
WANG, Catherine L.; AHMED, Pervaiz K. The development and validation of the organisational innovativeness construct using confirmatory factor analysis. European Journal of Innovation Management, [s.1.], v. 7, n. 4, p. 303-313, dez. 2004. Emerald. 